\title{
Significance of factor describing visual control in the second management principle of Toyota in the automotive supply industry
}

\author{
Krzysztof Mielczarek $^{1}$, Krzysztof Knop ${ }^{2}$ \\ ${ }^{1,2}$ Department of Production Engineering and Safety, Faculty of Management, Czestochowa University of Technology, Armii Krajowej 19B, \\ 42-200 Czestochowa, Poland, e-mail: mielczarek@zim.pcz.pl ${ }^{1}$,kknop@ poczta.fm²
}

\begin{abstract}
The article presents research results in a scope of evaluation importance in visual control usage in the production processes of enterprises from automotive industry. The significance of visual control in a production process was characterized. An innovative BOST questionnaire survey was described as a tool for transformation of Toyota's management principles into questions. The survey questions from BOST study were described, which is used in evaluation of the visual control importance with reference to the second Toyota's management principle (question E3). The analysis of respondents preference in ranging factors of the second Toyota's management principle was conducted using comparative evaluation of Thurstone's method, as well as the degree of similarity between these factors was indicated. A subjective factor was assessed by employees of automotive industry as one of less significant in the production process.
\end{abstract}

Key words - visual control, statistical analysis, BOST method, automotive supply industry

\section{Significance of visual control in pro- duction process}

Visual control is known as well as visibility management, management by visibility or management by sight. Visual control is a lean technique; a way of communicating; a type of control; a system; a type of workplace management; a method of problems visualization. The concept of visual controls is the major part of a Lean manufacturing system, which focuses on waste reduction (ORTIZ CH. O., PARK M. R. 2011)

Visual control is a system that helps organizations create and sustain a competitive advantage in two significant ways. First, it ensures that an organization's internal structure, management systems, work environment, and culture are aligned with its mission and values. Second, it focuses employees' attention on critical performance goals, making sure that employees know what is expected of them at all times and are committed to the organization's success (LIFF S., POSEY P. A. 2007). Visual control is the type of control that will enable even person such as the company president, or other upper-level executives who know very little about the plant, to apprehend a certain amount of important information about the plant (namely, the progress status of the manufacturing processes, the amount of raw materials and work-inprogress being held in inventories, the number of defects generated, which machines and equipment are out 
of production and why, and the like) merely by walking through the plant and observing it; which, in turn, will allow these executives to point out problems and make suggestions concerning how to deal with them.

Visual control is any communication device used in a work environment that shows how work should be done and whether it is deviating from the standard (LIKER J. K. 2005). Visual control includes measures, instruments or mechanisms, which were designed for the sake of management or operation of control (process) in order to fulfil the defined objectives. It is an important element in $5 \mathrm{~S}$ practice. Visual workplace is self-ordering, self-explanatory, self-regulating and self-improving work environment - where, whatever is supposed to happen, will invariably happen, a result of visual solutions. Visual control includes different approaches, which cause that the state of process is visible at first glance (MANN D. 2005).

Jeffrey K. Liker, an expert on the Toyota's production system, points at the basic aim of visual control, i.e. visual control, above all, is supposed to help to identify problems and to show divergences between objectives and the current situation. When deviations from standards are visible and obvious for everyone, there is a possibility of immediate corrective actions in order for these problems to be solved. According to Liker, the visual aspect of this control consists in the fact that it is possible to examine a process, a machine, an element of supplies, information or an employee performing a task, and to notice immediately a standard adopted for them along with possible deviation from it.

Masaki Imai, the world-famous kaizen expert, distinguished three basic objectives (principles) of visual control: first - indication of problems. If deviation from the norm cannot be detected, nobody can manage the process; second - help both employees and supervisors in staying alert as far as reality in the workplace is concerned (gemba). Visualization of deviations from the norm for all employees - managers, supervisors and linear employees - enables immediate corrective actions; third - show and explain the purpose of improvements. The existence and visualization of purpose are a basic motivator for people, as Imai states, "numbers aren't enough..., without purpose numbers are dead".
Based on literature analysis in the content of visual control (HIRANO H. 1995) it is possible to specify the following specific objectives of visual control: organization of workspace so that all people (even those from the outside) could state whether everything is going well or badly; without expert assistance; allowing an employee orientation in the new environment that is described, identified and ordered; simplification of determined events perception, and owing to that shortened response time of the operator to existing incident; showing the operation or work status in an easy to see format; providing instruction; providing information; causing that problems, irregularities, or deviation from standards are visible for everyone, i.e. corrective actions can be performed immediately; ensure immediate response from people.

\section{Idea of the second management prin- ciple of Toyota}

A survey and research method determined as BOST - the name of the is an acronym created from the first two letters of the name and surname of its creator, Stanislaw Borkowski, a professor of technical and economic sciences. The acronym, which is legally protected (BORKOWSKI S. 2012A), was formed as a result of the author's fascination in Toyota Motor Company, in its management and production system, enhanced after reading a book by Jeffrey Liker "The Toyota Way: 14 Management Principles from the World's Greatest Manufacturer".

BOST studies are aimed to prove that in enterprises operating in Poland, irrespective of conducted activity, the employees unconsciously use management principles about which perhaps they never heard. These are principles of Toyota's management principles (BORKOWSKI S. 2012B). In relation to BOST study over 50 publications presenting practical results of the use of this method in various organizations were used (BORKOWSKI S., KNOP K., RUTKOWSKI T. 2011). An issue of visual control evaluation in BOST questionnaire form appears in question E3. The content of question E3 is "a response" to the second Toyota's management principle, ordering "to create continuous process flow to bring problems to the surface". Area marked as E3 is described a set of six factors, among which is the factor of visual control usage (SW). The 
content of question E3 is: what is the most important factor in the production process? In the box write 1,2 , 3, 4, 5, 6 (6 the most important element) (BORKOWSKI S. 2012C).

\begin{tabular}{|l|l|l|}
\hline CP & $\begin{array}{l}\text { Continuous system of disclosuring } \\
\text { problems } \\
\text { Production interruption after detecting } \\
\text { quality problem } \\
\text { Standard tasks, processes, documents } \\
\text { Pelegate authority down } \\
\text { Applying exclusively a reliable tech- } \\
\text { SZ }\end{array}$ & $\begin{array}{l}\text { nology } \\
\text { Usage of visual control }\end{array}$ \\
\hline EU & ST
\end{tabular}

BOST questionnaire survey - Toyota's management principles in questions were conducted amongst 10 enterprises from the automotive industry. A research area included companies from the area of Silesian province in Poland. The research objects were direct suppliers (Tier 1) and companies from the second in the chain of subcontractors (Tier 2). A preliminary condition for classification of the companies to BOST study was confirmed information about implementation of visual control system in the workstations in the analysed company.

\section{Creation of significance series of discussed factors}

The analysis of the importance of visual control use in the production process of automotive industry was carried out. For that purpose, answers to question E3 were analyzed from BOST questionnaire form, which is a reply to the second Toyota's management principle. As a part of analysis in the obtained replies the structure of evaluations to subjective factor was presented. Analysis results were presented in Fig. 1.

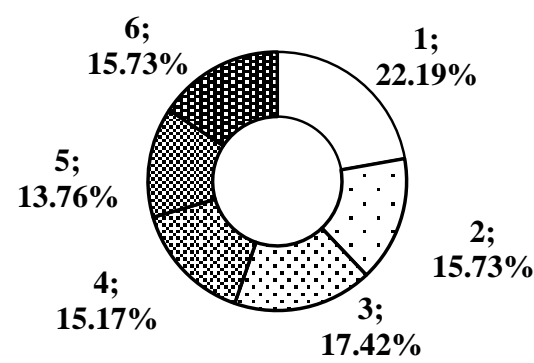

Fig. 1. Percentage ratings structure for the use of visual control (SW) factor.
Rating most often granted by respondents to subjective factor was "1" (22.19\% of readings), and most rarely - " 5 " (13.42\% of readings). Analysis of ratings distribution indicates intermodality, no consensus as to the importance of this factor in cross-section of all examined enterprises from the automotive industry.

Average rating to examine factor was $3.29 \pm 1.76$. The most frequently occurring value was 1 . Calculation results of such positional statistical parameters as median, quartiles and range were presented using box plot with reference to all factors of the production process (Fig. 2).

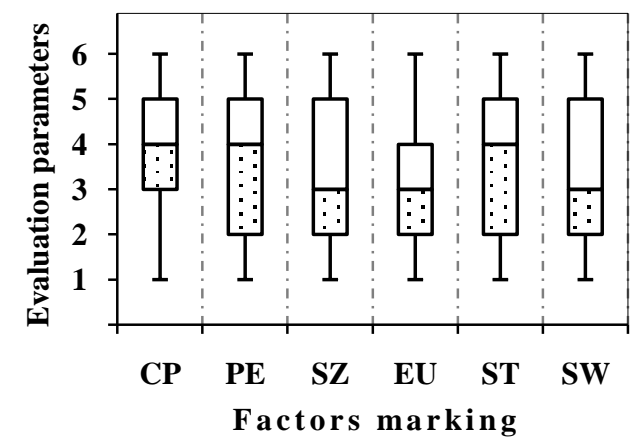

Fig. 2. Box plot diagrams for the factors of the second Toyota's management principle.

Box plot provided a lot of valuable information about rating distribution to the examined factor. Values of interquartile range shows that half of respondent replies were between the value of " 2 " and " 5 ". Median rating was " 3 ", i.e. half of polled employees pointed at lower than " 3 " and half at higher than " 3 ". Median value, which is closer to the first quartile $\mathrm{Q}_{1}$, indicates right-handed asymmetry of distribution in $50 \%$ central ratings. Identical height of tendrils and central location of box points at the symmetrical distribution of all ratings. A similarity in distribution of positional statistical parameters was recorded between the subjective factor and factor of standard processes, tasks and documents (SZ). In the following part of the article it was verified whether this relation is statistically significant. A place of subjective factor was analyzed amongst the remaining factors of the second Toyota's management principles in ranks of importance for individual ratings 1-6 (Table 1). Subjective factor SW was assessed as one of the most important in case of "1" and " 3 " rating and as one of the least important in case of "4", "5" and " 6 " rating. 
Table 1. Analysis of the causes and consequences of errors in the calculation of the bearing capacity of the slewing

\begin{tabular}{|c|c|c|c|c|c|c|}
\hline $\begin{array}{c}\text { Ran- } \\
\text { king }\end{array}$ & $\mathbf{1}$ & $\mathbf{2}$ & $\mathbf{3}$ & $\mathbf{4}$ & $\mathbf{5}$ & $\mathbf{6}$ \\
\hline $\mathbf{1}$ & EU & SW & SZ & CP & ST & PE \\
\hline $\mathbf{2}$ & SZ & EU & PE & ST & SW & CP \\
\hline $\mathbf{3}$ & EU & SW & ST & SZ & PE & CP \\
\hline $\mathbf{4}$ & SZ & PE & ST & SW & CP & EU \\
\hline $\mathbf{5}$ & CP & ST & PE & SW & SZ & EU \\
\hline $\mathbf{6}$ & CP & PE & ST & SW & SZ & EU \\
\hline
\end{tabular}

The analysis showed that SW factor was more preferred by respondents over only two factors of the production process i.e. delegate authority down (EU) and standard tasks, processes and documents (SZ). In other cases it is a less preferred factor of the production process. A graphical compartment of onedimensional marking scale of comparative assessments was created (Fig. 3).

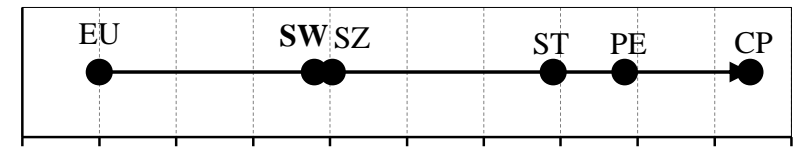

$\begin{array}{lllllllll}0 & 0,05 & 0,10 & 0,15 & 0,20 & 0,25 & 0,30 & 0,35 & 0,40\end{array}$

"Distance" between factors

Fig. 3. One-dimensional marking scale of comparative assessments of second Toyota's management principle factors.

From Fig. 3 results that are possible to distinguish four groups of preferred factors in the structure of factors of the second Toyota's management principle in the analyzed industry. The least preferred factor (the first on the left) is delegate authority down (EU), rank among the second group of preferred factors are two factors i.e. standard tasks, processes and documents (SZ) and a subjective factor SW (degree of similarity between these factors is the greatest), the third group of factors includes production interruption after detecting quality problem (PE) and applying exclusively a reliable technology (ST), and the most preferred factor among all examined industry turned out to be continuous system of discloursing problems (CP).

\section{Conclusions}

An analysis of collected responses from employees of 10 companies from the automotive industry was carried out. Percentage structure of votes to the factor of visual control used in the production process was described. Statistical analysis of a reply to examined factor was carried out using statistical parameters of position and box-tendrils graphs. A place of subjective factor was analyzed amongst factors of the second Toyota's management principle in ranges of the importance for individual evaluations. Comparative evaluation of the Thurstone's method was used in order to create a scale of factor preferences of the second Toyota's management principle. The analysis showed that subjective factor was the most similar in evaluations to the factor of standard tasks, processes and documents (SZ). The subjective factor SW is preferred only by $0.28 \%$ from the SZ factor. The SW factor was the one of least significant in the production process factors of analysed companies from automotive industry.

\section{Literature}

1. Ortiz Ch. O., Park M. R. 2011. Visual Controls. Applying Visual Management to the Factory. Productivity Press, New York.

2. Liff S., Posey P. A. 2007. Seeing is Believing: How the New Art of Visual Management Can Boost Performance Throughout Your Organisation. AMACOM/American Management Association, New York.

3. LIKER J. K. 2005. The Toyota Way: 14 Management Principles from the World's Greatest Manufacturer. MT Biznes. Warsaw. (in Polish).

4. Mann D. 2005. Creating a Lean Culture Tools to Sustain Lean Conversion. Productivity Press. New York.

5. HIRANO H. 1995. 5 Pillars of the Visual Workplace: The Sourcebook for 5S Implementation. Productivity Press. Portland.

6. BORKOWSKI S. 2012A. Documents containing invented term (TOYOTARYZM) and containing the name and the structure of elaborated method (BOST). Confirmation of the date. „AAK” Patent Law Firm s.c. Czestochowa. (in Polish).

7. BoRKOWSKI S. 2012B. Toyotaryzm. Toyota's management principles in questions. PTM. Warsaw. (in Polish).

8. BoRKOWSKI S. 2012C. Toyotaryzm. Results of the BOST method. PTM, Warsaw. (in Polish).

9. BorkOWsKi S., KNOP K., RUTKOWSKI T. 2011. Meaning of Visual Control Types in Production Improvement. Chapter 9. In: Production Improvement. Ed.: Borkowski S., Konstanciak M. TRIPSOFT. Trnava. 